\title{
IATROGENIC PNEUMOCEPHALUS AND HYPERBARIC OXYGEN THERAPY A CASE REPORT
}

R. Santos Pinheiro, A. Vasconcelos Pereira, B. Aguiar Tavares da Silva, L. Rego, R. Veiga, N. Costa

Vila Franca de Xira Hospital, Anesthesiology, Vila Franca de Xira, Portugal

\section{BACKGROUND}

Pneumocephalus is a rare but potentially serious complication of epidural block. Hyperbaric oxygen therapy (HBOT) accelerates the air absorption in patients with persistent and symptomatic pneumocephalus, leading to clinical and radiological improvement.

\section{CASE-REPORT}

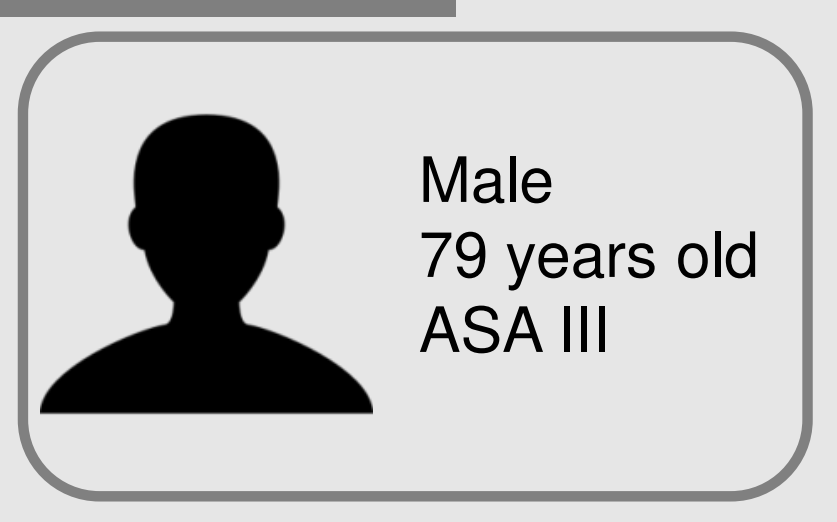

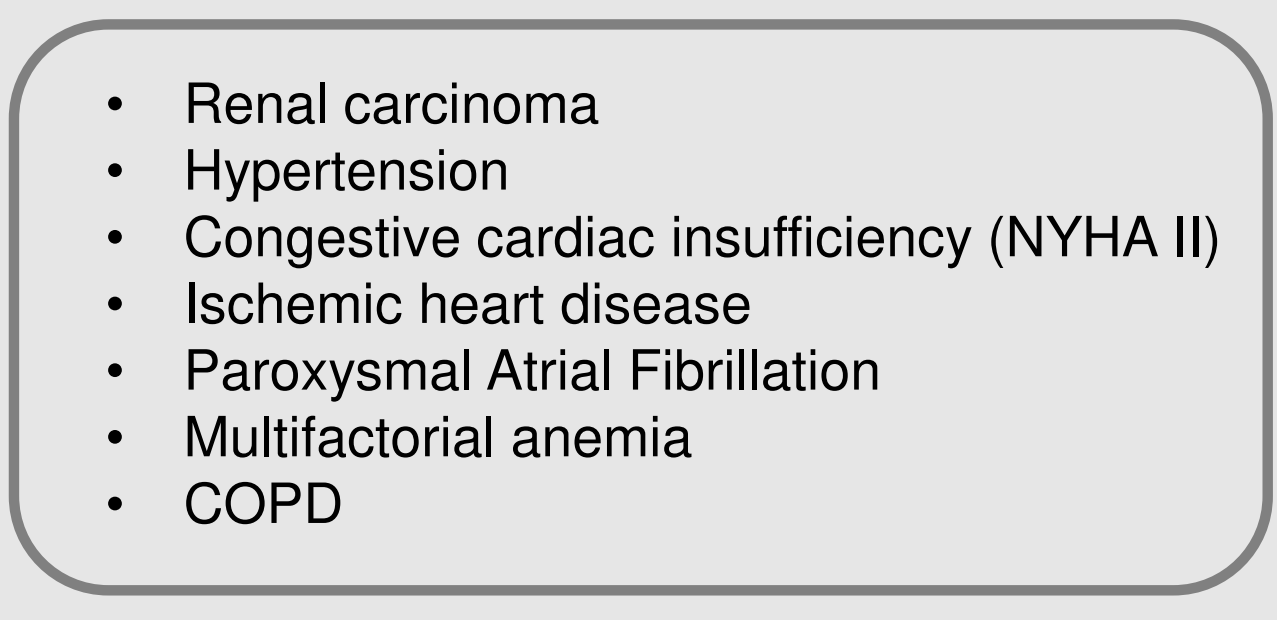

INTRAOPERATIVE

Lumbar epidural + General Anesthesia

\section{Surgical Procedure}

Left radical nephrectomy

Transurethral resection of bladder

Informed consent obtained

$\checkmark 1^{\text {st }}$ attempt: L3-L4 with loss-of-resistance to saline technique $=>$ accidental dural puncture

$\checkmark 2^{\text {nd }}$ attempt: The catheter was then placed at L4-L5 with loss-of-resistance to air technique

$\checkmark$ It was used intraoperatively without complications

\section{2,5 hours surgery without any other complication}

\section{POSTOPERATIVE}

The patient was admitted in the IMCU, stable and without neurological signs.

Epidural infusion was started using a $50 \mathrm{~mL}$ infusion syringe system with $1,3 \mathrm{mg} / \mathrm{mL}$ levobupivacaine and $40 \mathrm{mcg} / \mathrm{mL}$ morphine at $2 \mathrm{~mL} / \mathrm{h}$.

\section{$2 \mathrm{H}$ after surgery}

Confusion/agitation (RASS+2), vertical nystagmus and paraparesis (RIM2, LIM1)
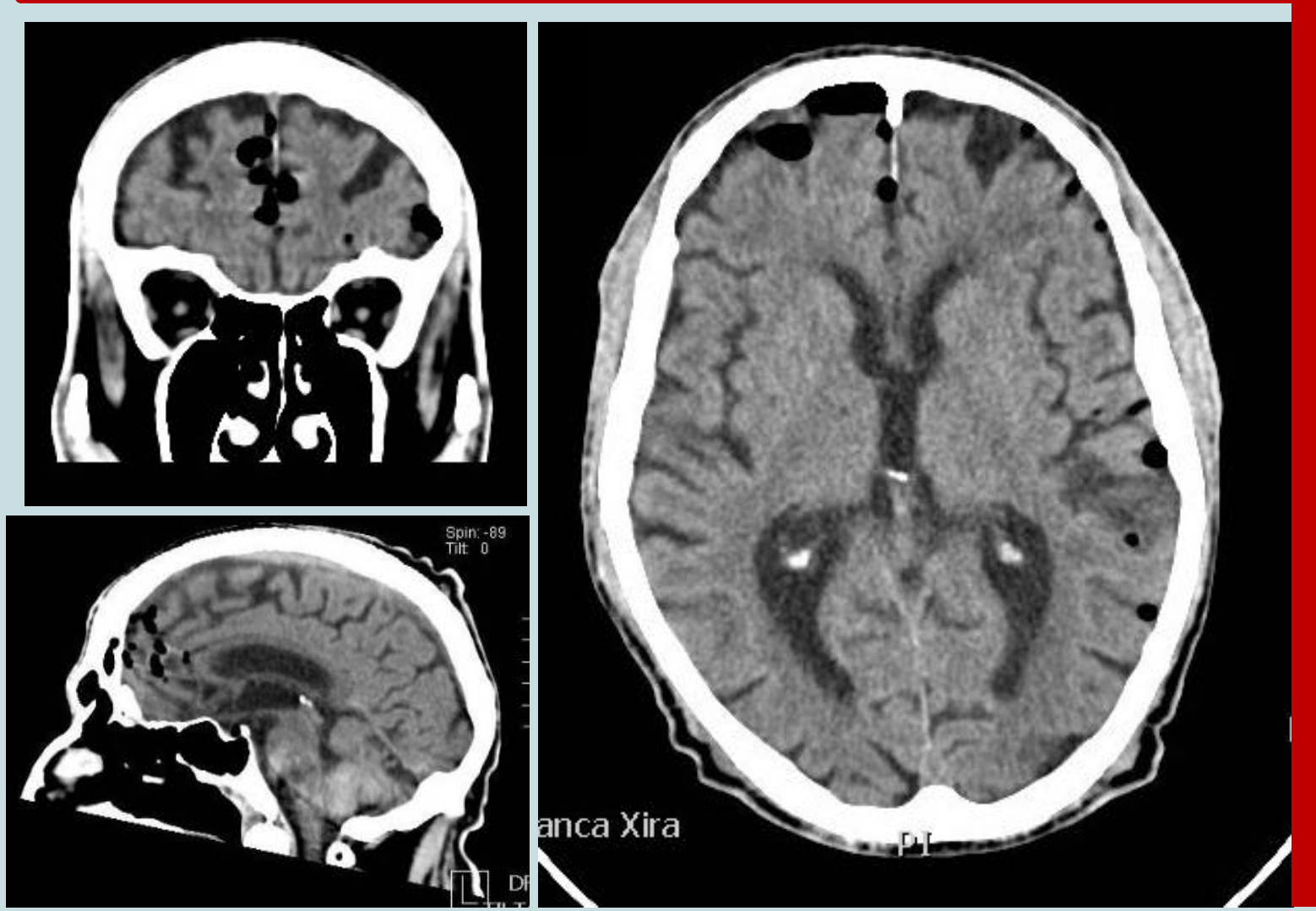

\section{After treatment}

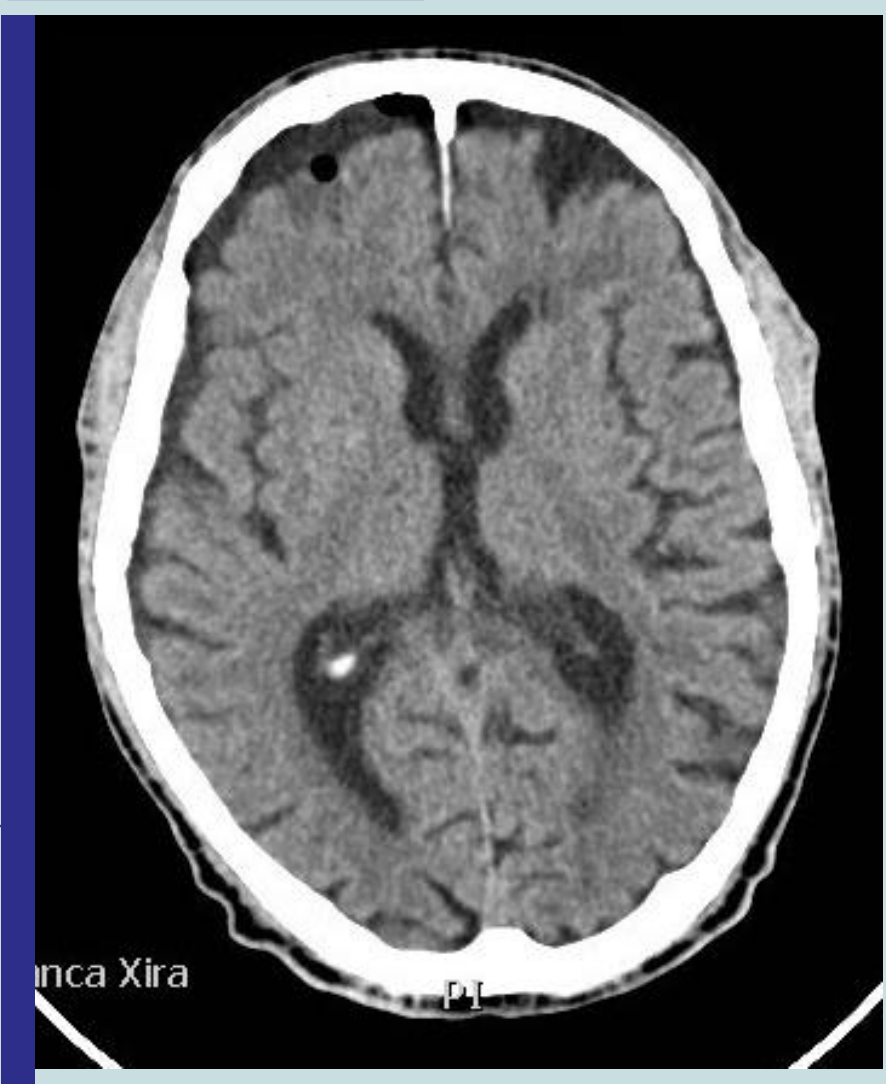

Total resolution of deficits.

Discharged on the 7th postoperative-day.

\section{DISCUSSION}

The presence of air in the intracranial cavity is called pneumocephalus and it is usually caused by trauma, surgery procedures or during neuroaxial approaches.

Loss-of-resistance to air technique increases the likelihood of pneumocephalus in case of accidental dural puncture.

HBOT has been successfully used as a treatment for symptomatic pneumocephalus, shortening the length of hospital stay and decreasing the incidence of meningitis.

In this case report one single session of HBOT lead to radiological improvement and clinical resolution. 